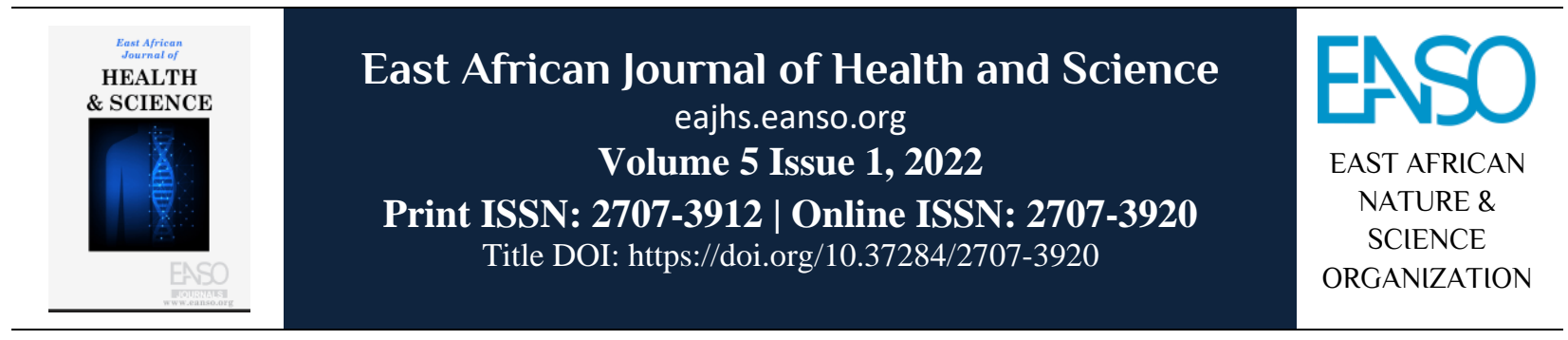

Original Article

\title{
Prevalence of Depression among Patients with Chronic Kidney Disease (CKD) at the Kenyatta National Hospital.
}

\author{
Dr. Angeline Mutindi Kioko, MMed ${ }^{1}$, Dr. Teresia Ndilu Mutavi, PhD ${ }^{12 *} \&$ Dr. Pius Akivanga \\ Kigamwa, MMed ${ }^{12}$ \\ ${ }^{1}$ University of Nairobi, P. O. Box 30197, GPO, Nairobi; Kenya. \\ ${ }^{2}$ Kenyatta National Hospital, P. O. Box 20723 - 00202, Nairobi; Kenya. \\ *Author for correspondence ORCID ID: https://orcid.org/0000-0002-2585-6556; email: mutavi.teresia@uonbi.ac.ke.
}

Article DOI: https://doi.org/10.37284/eajhs.5.1.571

\section{Date Published: ABSTRACT}

08 March 2022 Background: Depression is a common comorbidity among patients with chronic kidney disease (CKD). Preceding studies indicates that this

Keywords: condition causes increased mortality and is also linked to poor quality of life. The study aimed to establish the occurrence of depression among

Chronic Kidney Disease,

Depression,

Quality of Life,

PHQ 9. patients with chronic kidney disease in Kenyatta National Hospital in Kenya. Method: The study was carried out at the Kenyatta National Hospital in Kenya. The study was done at the renal unit and general medical wards of the hospital and was a cross-sectional descriptive study. The study enrolled 289 patients with CKD who met the inclusion criteria on follow up for kidney transplant and dialysis at the renal unit, those on outpatient follow up at the renal clinic and patients with CKD admitted in the medical wards. The participants were enrolled using systematic random sampling. They were then interviewed using a researcher designed a sociodemographic questionnaire with clinical characteristics and the Beck Depression Inventory-II. IBM Statistics Software Version 21 was used to analyse data and the results reported in narratives, tables and charts. Results: A total of $169(58.5 \%)$ participants were male, while $120(41.5 \%)$ were female. Study participants had a mean age of 45.9 years. The prevalence of depression (borderline clinical depression to extreme depression) was found to be $28.4 \%$. $24.9 \%$ of participants had mild mood disturbances and $46.7 \%$ did not have depression. The most common symptoms of depression among the participants were loss of energy as reported by $78.5 \%$ of them and increased fatigue which was reported by $77.9 \%$ of the research participants. Conclusion: There is a high prevalence of depression among patients with

36 This work is licensed under a Creative Commons Attribution 4.0 International License. 
CKD and patients should be managed effectively for CKD and any other co-existing comorbidity to improve their health outcomes and their quality of life.

\section{APA CITATION}

Kioko, A. M., Mutavi, T. N. \& Kigamwa, P. A. (2022). Prevalence of Depression among Patients with Chronic Kidney Disease (CKD) at the Kenyatta National Hospital. East African Journal of Health and Science, 5(1), 36-48. https://doi.org/10.37284/eajhs.5.1.571.

\section{CHICAGO CITATION}

Kioko, Angeline Mutindi, Teresia Ndilu Mutavi, \& Pius Akivanga Kigamwa. 2022. "Prevalence of Depression among Patients with Chronic Kidney Disease (CKD) at the Kenyatta National Hospital.". East African Journal of Health and Science 5 (1), $36-$ 48. https://doi.org/10.37284/eajhs.5.1.571.

\section{HARVARD CITATION}

Kioko, A. M., Mutavi, T. N., \& Kigamwa, P. A. (2022) "Prevalence of Depression among Patients with Chronic Kidney Disease (CKD) at the Kenyatta National Hospital.”, East African Journal of Health and Science, 5(1), pp. 36-48. doi: 10.37284/eajhs.5.1.571.

\section{IEEE CITATION}

A. M. Kioko, T. N. Mutavi, \& P. A. Kigamwa, "Prevalence of Depression among Patients with Chronic Kidney Disease (CKD) at the Kenyatta National Hospital.”, EAJHS, vol. 5, no. 1, pp. 36-48, Mar. 2022.

\section{MLA CITATION}

Kioko, Angeline Mutindi, Teresia Ndilu Mutavi, \& Pius Akivanga Kigamwa. "Prevalence of Depression among Patients with Chronic Kidney Disease (CKD) at the Kenyatta National Hospital.". East African Journal of Health and Science, Vol. 5, no. 1, Mar. 2022, pp. 36-48, doi:10.37284/eajhs.5.1.571.

\section{INTRODUCTION}

Chronic Kidney Disease (CKD) is a major public health concern affecting millions of people globally and its treatment presents a huge burden for these patients as they are required to make changes in life to adapt socially. This adaptation or lack thereof has been associated with increased incidences of depression with a prevalence of $19-68 \%$ for patients who are on haemodialysis (Liu et al., 2017; Shirazian et al., 2017). Further, a double impact of CKD and depression has been reported where CKD increases the risk of depression while depression reduces the adherence to medication by patients with CKD and leads to low quality of life, which is made worse by the high costs associated with its treatment (Bautovich et al., 2014; Kokoszka et al., 2016; Da Silva Junior et al., 2017). Although renal complications are caused by multiple noncommunicable diseases, renal disease remains one of the most neglected chronic diseases with people suffering from renal disease lacking access to care (Dhondup et al., 2018). Kidney disease increases the risks associated with hypertension, heart disease, Human Immunodeficiency Virus (HIV) and infectious diseases including malaria thereby contributing to the global burden of mortality (Couser et al., 2011).

Reduced glomerular filtration rates were directly estimated to cause the loss of 18 million years of life, 19 million Disability Adjusted Life Years (DALYs) and 1.2 million deaths globally in 2015(Couser et al., 2011). Furthermore, Chronic Kidney Disease is associated with eight to ten times the prevalence of cardiovascular mortality in individuals with comorbid hypertension and diabetes. In addition, about 2 million people need a renal replacement for the sustenance of life globally (Dhondup et al., 2018). Most patients with CKD, due to symptoms that are prevalent and bothersome including impairment, mental and emotional fatigue, physical fatigue, decreased motivation and apathy, have a low quality of life. These factors are a prerequisite to the development of depression which has been found to affect about $25 \%$ of hospitalised CKD patients (Fischer et al., 2011; Palmer et al., 2013). Further, it is reported that fatigue is associated with 76- $96 \%$ of patients who have been diagnosed with clinical depression. However, in most cases, depression is not recognised for patients with $\mathrm{CKD}$ and therefore goes untreated (Farragher et al., 2017). 
Research has shown that there is a correlation between the diagnosis of chronic disease and the development of psychiatric disorders. People who have been diagnosed with a chronic disease are 1.44 times more likely to develop depression, unlike the general population. Psychological distress in these patients has a prevalence of up to $52 \%$ as shown in some studies (Sfyrkou, 2015). The physical and biological changes that result from dialysis treatment for people with renal failure have been reported to cause depression. Further, people with renal failure who are not receiving dialysis treatment are three times more likely to have depression, unlike the common population (Shirazian et al., 2017).

Globally, there is a prevalence of $25 \%$ of major depressive disorder for individuals with long term kidney impairment compared to $7 \%$ prevalence for the general population (Gregg et al., 2020). In a study done in the USA for Major Depressive Episode (MDE) and renal disease, at baseline, there was a prevalence of $21 \%$ for Major Depressive Episode (MDE). After one year of follow up, the prevalence for MDE was $61 \%$ with death, dialysis initiation and hospitalisation occurring more for those with MDE (Hedayati et al., 2010). In the Netherlands, there was a $34 \%$ incidence of depression among patients with CKD, 31\% occurrence of anxiety and $23 \%$ prevalence for both depression and anxiety (Loosman et al., 2015).

In Asia, a study using the Taiwanese Depression Questionnaire found a prevalence of depression of $21 \%$ at the beginning and $31 \%$ when the study ended (Chiang et al., 2015). These results were similar to studies done in China, where the prevalence of depression was between 23\%- 29\% for patients on haemodialysis (Liu et al., 2017). Although there are very few studies done in Africa exploring the occurrence of depression among patients with CKD, a study done in Nigeria on stages 3-5 of renal disease found a prevalence of $23 \%$, which is similar to most of the studies done globally, compared to $2 \%$ for the general population (Amira, 2011). Research conducted in Ghana found an incidence of $45 \%$ of depression amid patients with CKD with a $19 \%$ low overall standard of life based on the World Health Organization Quality of Life (WHOQOL) instrument (Ganu et al., 2018). This study aimed to establish the frequency of depression among patients with CKD at Kenyatta National Hospital in Kenya.

\section{METHODOLOGY}

The researchers conducted a cross-sectional descriptive study at Kenyatta National Hospital, the largest Teaching and Referral hospital in Kenya. This facility started to operate in 1901 with an initial bed capacity of 40 . The hospital has a total of 50 wards, 22 outpatient clinics, 24 theatres (16 specialised) and the Accident and Emergency Department. It has 8 adult medical wards situated on the seventh and eighth floors. On average, the medical wards host around 400 patients in total. Patients with renal issues who require admission are admitted to any of the medical wards. This facility has a total of 209 beds for the private wing out of a possible 1800 bed capacity. The hospital accommodates between 2,500 and 3,000 patients in its wards on any given day. The hospital takes care of over 80,000 inpatients and over 500,000 outpatients on average every year with a renal unit that was opened in 1984. Within this unit, dialysis is done daily. There is a renal transplant clinic every Tuesday and a renal clinic run every Friday morning at clinic no. 24. About 50 patients are dialysed every day and on Friday mornings at the clinic, an average of 60 patients are seen.

Ethical approval was sought from the University of Nairobi/Kenyatta National Hospital Ethics Review Committee [P491/09/2020]. Participants for this study were adult renal patients admitted to the medical wards, CKD Patients attending the renal outpatient clinic and patients on follow up for dialysis and kidney transplant at the renal unit in KNH who gave informed written consent. Those who were too sick or did not give informed consent were excluded. To calculate the study sample size, the Naing formula was used (Naing et al., 2006). 1.96 the critical value on a standard normal distribution corresponding to a $95 \%$ confidence level. $25 \%$, the estimated proportion of patients who have a diagnosis of major depressive disorder in chronic kidney disease globally. A total of 289 patients with CKD were sampled.

A researcher premeditated questionnaire that captured data classification and appropriate demographic variables like sex, age, marital status, 
religion, educational level, occupation and the approximate amount of income was used. It also captured past psychiatric factors, substance use history, mental illness history of the family and other comorbidities.

Depression was assessed using the Beck Depression Inventory (BDI-II) (Beck et al., 1996). This is a 21item scale that measures the symptomatology of depression. Every question on the BDI-II is scored from 0 - 3, where the higher number indicates symptom severity. From the 21 items on the questionnaire, their range of scores is between 0- 63 . The clinical cut-off points include; mild mood disturbance (11-16), borderline clinical depression (17-20), moderate depression (21-30), severe depression (31-40) and extreme depression (40-63). It has high internal consistency, and Cronbach's $\alpha=$ 92. The BDI -II has been used in Kenya and other nations (Musyimi et al., 2017; Ndetei et al., 2009).

A total of five days of the week from Monday to Friday were set aside to interview patients for three months, starting 01/03/2021 to 31/05/2021. Monday, Tuesday and Thursday, the researchers sat at the renal unit at $\mathrm{KNH}$ daily from 8:00 am to 5:00 $\mathrm{pm}$ and interviewed those on follow up for dialysis and kidney transplant who met the inclusion criteria. On Wednesday, the researchers interviewed patients in the ward between 8:00 am to 5:00 pm who met the inclusion criteria. On Friday, the researchers sat at Renal Clinic No. 24 and interviewed those who met the inclusion criteria.

The study employed a systematic random sampling method with substitution to recruit individuals who came for follow-up as well as those admitted in the wards. The first recruitment procedure involved the researchers interviewing every third patient who came for clinic, dialysis and kidney transplant follow up at the renal unit at KNH. Any patient who did not qualify or declined to participate was replaced with the next one on the list who qualified. The second recruitment procedure involved CKD patients in the wards. The researchers interviewed every third patient that was admitted in the wards and who met the inclusion criteria. Any selected patient who declined to participate was replaced with the next patient on the list who qualified. The study was conducted at the renal unit and general medical wards in Kenyatta National Hospital. To ensure privacy and confidentiality, the interviews were done in one of the consultation rooms at the unit. In the wards, the interviews were done at the bedside of the patients.

Due to COVID-19, data collected at the follow-up clinic and in the ward was in adherence to the set public health directives, policies and recommendations. During face-to-face visits, appropriate infection prevention control measures including temperature checks, washing and sanitising of hands, wearing of a 3-ply face mask, and social distancing of 1.5 meters during the interviews was observed.

Descriptive statistics was done in areas where separate variables were put in the form of a summary with frequencies and percentages. As the main variable of interest, factors associated with depression were recognised by the use of Chisquared tests and Fisher's exact tests for nominal variables and $\mathrm{T}$-tests for continuous variables was used. Multivariate analysis was done and we attuned for confounders and effect modifiers in the model to establish independent factors related to depression by use of binary stepwise backward logistic regression. All analysis was done by use of IBM Statistics Software Version 21 and presented using tables, graphs and in prose.

\section{RESULTS}

Two hundred and eighty-nine participants were enrolled on the study. The response rate was $100 \%$, with the mean age of participants recorded at 45.9 years. 
East African Journal of Health and Science, Volume 5, Issue 1, 2022

Article DOI: https://doi.org/10.37284/eajhs.5.1.571

Table 1: Socio-demographic Data

\begin{tabular}{|c|c|c|c|}
\hline & & frequency & $\%$ \\
\hline \multirow{4}{*}{ Age category } & $18-24$ & 23 & 8.0 \\
\hline & $25-35$ & 56 & 19.4 \\
\hline & $36-50$ & 110 & 38.1 \\
\hline & Above 50 years & 100 & 34.6 \\
\hline \multirow{2}{*}{ Sex } & Male & 169 & 58.5 \\
\hline & Female & 120 & 41.5 \\
\hline \multirow{5}{*}{ Marital status } & Single & 66 & 23.0 \\
\hline & Married & 206 & 71.8 \\
\hline & Separated & 11 & 3.8 \\
\hline & Widowed & 4 & 1.4 \\
\hline & Cohabiting & 0 & .0 \\
\hline \multirow{4}{*}{ Level of Education } & Lack of formal education & 5 & 1.7 \\
\hline & Primary & 71 & 24.6 \\
\hline & Secondary & 141 & 48.8 \\
\hline & Tertiary & 72 & 24.9 \\
\hline \multirow{6}{*}{ Occupation } & Student & 19 & 6.6 \\
\hline & Formal employment & 54 & 18.7 \\
\hline & Informal employment & 38 & 13.1 \\
\hline & Businessperson & 96 & 33.2 \\
\hline & Unemployed & 82 & 28.4 \\
\hline & More than one category & 0 & .0 \\
\hline \multirow{5}{*}{ Income } & Less than 6000 & 141 & 49.0 \\
\hline & $6000-10000$ & 42 & 14.6 \\
\hline & $10000-40000$ & 65 & 22.6 \\
\hline & $40000-100000$ & 34 & 11.8 \\
\hline & $>100000$ & 6 & 2.1 \\
\hline \multirow{4}{*}{ Religion } & Catholic & 106 & 36.8 \\
\hline & Protestant & 167 & 58.0 \\
\hline & Muslim & 13 & 4.5 \\
\hline & Others & 2 & .7 \\
\hline
\end{tabular}

As shown in Table 1 above, 23 (8\%) of the participants were 18-24 years, $56(19.4 \%)$ were 25 35 years, $110(38.1 \%)$ were 36-50 years, while 100 $(34.6 \%)$ were above 50 years. Additionally, as shown in Table 1 above, $169(58.5 \%)$ of the participants were male, while $120(41.5 \%)$ were female. Almost three-quarters 206 (71.8\%) were married, $66(23 \%)$ were single, $11(3.8 \%)$ were separated and $4(1.4 \%)$ were widowed. $5(1.7 \%)$ participants had no formal education, 71 (24.6\%) had attained education up to the Primary school level and 141 (48.8\%) had attained education up to secondary school level. $72(24.9 \%)$ had attained education up to the tertiary level. A total of 92 (31.8\%) participants were employed. 96 (33.2\%) of the participants were in business and those who were unemployed were 82 (28.4\%). 19 (6.6\%) participants were students. Almost half of the participants $(141,49 \%)$ were earning less than KES 6,000, $42(14.6 \%)$ were earning approximately KES $6000-10000,65(22.6 \%)$ were earning KES $10000-40000$, 34(11.8\%) were earning KES 40000100000 and only $6(2.1 \%)$ were earning more than KES 100000. The most common religion was Christian with 106 (36.8\%) being catholic and 167 $(58.0 \%)$ being protestant. There were only 13 (4.5\%) Muslims.

40 This work is licensed under a Creative Commons Attribution 4.0 International License. 
East African Journal of Health and Science, Volume 5, Issue 1, 2022

Article DOI: https://doi.org/10.37284/eajhs.5.1.571

\section{Depression Symptoms}

Table 2: Depression Symptoms

\begin{tabular}{|c|c|c|c|}
\hline \multicolumn{2}{|c|}{ Depression Symptoms } & \multirow{2}{*}{$\begin{array}{l}\mathbf{N} \\
168\end{array}$} & \multirow{2}{*}{$\begin{array}{l}\% \\
58.1\end{array}$} \\
\hline \multirow{4}{*}{ Sadness } & I do not feel sad & & \\
\hline & I feel sad much of the time & 106 & 36.7 \\
\hline & I am sad all the time & 12 & 4.2 \\
\hline & I am so sad or unhappy that I can't stand it & 3 & 1.0 \\
\hline \multirow{4}{*}{ Pessimism } & I am not discouraged about my future & 204 & 70.6 \\
\hline & I feel more discouraged about my future than I used to & 72 & 24.9 \\
\hline & I do not expect things to work out for me & 8 & 2.8 \\
\hline & I feel my future is hopeless and will only get worse & 5 & 1.7 \\
\hline \multirow{4}{*}{ Past failure } & I do not feel like a failure & 219 & 75.8 \\
\hline & I have failed more than I should have & 29 & 10.0 \\
\hline & As I look back, I see a lot of failures & 34 & 11.8 \\
\hline & I feel I am a total failure as a person & 7 & 2.4 \\
\hline \multirow{4}{*}{$\begin{array}{l}\text { Loss of } \\
\text { pleasure }\end{array}$} & I get as much pleasure as I ever did from the things I enjoy & 118 & 40.8 \\
\hline & I don't enjoy things as much as I used to & 101 & 34.9 \\
\hline & I get very little pleasure from the things I used to enjoy & 63 & 21.8 \\
\hline & I can't get any pleasure from the things I used to enjoy & 7 & 2.4 \\
\hline \multirow{4}{*}{ Guilty feeling } & I don’t feel particularly guilty & 207 & 71.6 \\
\hline & I feel guilty over many things I have done or should have done & 67 & 23.2 \\
\hline & I feel quite guilty most of the time & 14 & 4.8 \\
\hline & I feel guilty all of the time & 1 & .3 \\
\hline \multirow{4}{*}{$\begin{array}{l}\text { Punishment } \\
\text { Feelings }\end{array}$} & I don't feel I am being punished & 230 & 79.6 \\
\hline & I feel I may be punished & 35 & 12.1 \\
\hline & I expect to be punished & 1 & .3 \\
\hline & I feel I am being punished & 23 & 8.0 \\
\hline \multirow{4}{*}{ Self-Dislike } & I feel the same about myself as ever & 230 & 79.9 \\
\hline & I have lost confidence in myself & 29 & 10.1 \\
\hline & I am disappointed in myself & 17 & 5.9 \\
\hline & I dislike myself & 12 & 4.2 \\
\hline \multirow{4}{*}{$\begin{array}{l}\text { Self- } \\
\text { Criticalness }\end{array}$} & I don't criticise or blame myself more than usual & 233 & 80.6 \\
\hline & I am more critical of myself than I used to be & 33 & 11.4 \\
\hline & I criticise myself for all of my faults & 15 & 5.2 \\
\hline & I blame myself for everything bad that happens & 8 & 2.8 \\
\hline \multirow{4}{*}{$\begin{array}{l}\text { Suicidal } \\
\text { Thoughts or } \\
\text { Wishes }\end{array}$} & I don't have any thoughts of killing myself & 265 & 91.7 \\
\hline & I have thoughts of killing myself, but I would not carry them out & 22 & 7.6 \\
\hline & I would like to kill myself & 1 & .3 \\
\hline & I would kill myself if I had the chance & 1 & .3 \\
\hline \multirow{4}{*}{ Crying } & I don't cry any more than I used to & 209 & 72.3 \\
\hline & I cry more than I used to & 51 & 17.6 \\
\hline & I cry over every little thing & 7 & 2.4 \\
\hline & I feel like crying, but I can't & 22 & 7.6 \\
\hline \multirow{4}{*}{ Agitation } & I am no more restless or wound up than usual & 160 & 55.4 \\
\hline & I feel more restless or wound up than usual & 93 & 32.2 \\
\hline & I am so restless or agitated it's hard to stay still & 29 & 10.0 \\
\hline & I am so restless or agitated that I have to keep moving or doing something & 7 & 2.4 \\
\hline
\end{tabular}

41 This work is licensed under a Creative Commons Attribution 4.0 International License. 
East African Journal of Health and Science, Volume 5, Issue 1, 2022

Article DOI: https://doi.org/10.37284/eajhs.5.1.571

\begin{tabular}{|c|c|c|c|}
\hline \multicolumn{2}{|c|}{ Depression Symptoms } & \multirow{2}{*}{$\begin{array}{l}\mathbf{N} \\
192\end{array}$} & \multirow{2}{*}{$\begin{array}{l}\% \\
66.4\end{array}$} \\
\hline & I have not lost interest in other people or activities & & \\
\hline Loss of & I am less interested in other people or things than before & 71 & 24.6 \\
\hline \multirow[t]{2}{*}{ Interest } & I have lost most of my interest in other people or things & 22 & 7.6 \\
\hline & It's hard to get interested in anything & 4 & 1.4 \\
\hline \multirow{4}{*}{ Indecisiveness } & I make decisions about as well as ever & 213 & 73.7 \\
\hline & I find it more difficult to make decisions than usual & 54 & 18.7 \\
\hline & I have much greater difficulty in making decisions than I used to & 17 & 5.9 \\
\hline & I have trouble making any decisions & 5 & 1.7 \\
\hline \multirow{4}{*}{ Worthlessness } & I do not feel I am worthless & 247 & 85.5 \\
\hline & I don't consider myself as worthwhile and useful as I used to & 22 & 7.6 \\
\hline & I feel more worthless as compared to others & 13 & 4.5 \\
\hline & I feel utterly worthless & 7 & 2.4 \\
\hline \multicolumn{2}{|c|}{ Loss of energy I have as much energy as ever } & 62 & 21.5 \\
\hline & I have energy than I used to have & 133 & 46.0 \\
\hline & I don't have enough energy to do very much & 87 & 30.1 \\
\hline & I don't have enough energy to do anything & 7 & 2.4 \\
\hline \multirow{7}{*}{$\begin{array}{l}\text { Changes in } \\
\text { sleeping } \\
\text { pattern }\end{array}$} & I have not experienced any change in my sleeping & 106 & 36.7 \\
\hline & I sleep somewhat more than usual & 34 & 11.8 \\
\hline & I sleep somewhat less than usual & 80 & 27.7 \\
\hline & I sleep a lot more than usual & 17 & 5.9 \\
\hline & I sleep a lot less than usual & 44 & 15.2 \\
\hline & I sleep most of the day & 1 & .3 \\
\hline & I wake up 1-2 hours early and can't get back to sleep & 7 & 2.4 \\
\hline \multirow[t]{4}{*}{ Irritability } & I am not more irritable than usual & 153 & 52.9 \\
\hline & I am more irritable than usual & 82 & 28.4 \\
\hline & I am much more irritable than usual & 46 & 15.9 \\
\hline & I am irritable all the time & 8 & 2.8 \\
\hline \multirow{6}{*}{$\begin{array}{l}\text { Changes in } \\
\text { appetite }\end{array}$} & I have not experienced any change in my appetite & 119 & 41.3 \\
\hline & My appetite is somewhat less than usual & 90 & 31.3 \\
\hline & My appetite is much less than before & 55 & 19.1 \\
\hline & My appetite is much greater than usual & 16 & 5.6 \\
\hline & I have no appetite at all & 6 & 2.1 \\
\hline & I crave food all the time & 2 & .7 \\
\hline \multicolumn{2}{|c|}{ Concentration I can concentrate as well as ever } & 160 & 55.4 \\
\hline \multirow{3}{*}{ difficulty } & I can’t concentrate as well as usual & 92 & 31.8 \\
\hline & It's hard to keep my mind on anything for very long & 35 & 12.1 \\
\hline & I find I can't concentrate on anything & 2 & .7 \\
\hline \multirow{4}{*}{$\begin{array}{l}\text { Tiredness or } \\
\text { fatigue }\end{array}$} & I am no more tired or fatigued than usual & 64 & 22.1 \\
\hline & I get more tired or fatigued more easily than usual & 144 & 49.8 \\
\hline & I am too tired or fatigued to do a lot of the things I used to do & 69 & 23.9 \\
\hline & I am too tired or fatigued to do most of the things I used to do & 12 & 4.2 \\
\hline \multicolumn{2}{|c|}{ Loss of interestI have not noticed any recent change in my interest in sex } & 99 & 35.7 \\
\hline \multirow{4}{*}{ in sex } & I am less interested in sex than I used to be & 93 & 33.6 \\
\hline & I am much less interested in sex now & 50 & 18.1 \\
\hline & I have lost interest in sex completely & 35 & 12.6 \\
\hline & Mean $\quad$ Standard Deviation & \multicolumn{2}{|c|}{ Percentile 75} \\
\hline Total Score & 8.7 & \multicolumn{2}{|c|}{18.0} \\
\hline
\end{tabular}

42 This work is licensed under a Creative Commons Attribution 4.0 International License. 
A total of 168 (58.1\%) did not report any sadness, $204(70.6 \%)$ did not report any discouragement about the future, $219(75.8 \%)$ did not report feeling like a failure, $118(40.8 \%)$ reported no changes in things that gave them pleasure, 207 (71.6\%) didn't report feeling guilty, 230 (79.6\%) did not feel like they were being punished, 230 (79.9\%) did not report self-dislike, $233(80.6 \%)$ did not report selfcriticalness, 265 (91.7\%) did not report suicidal thoughts, $209(72.3 \%)$ reported that they did not feel like crying more than before, $160(55.4 \%)$ did not report unusual agitation, $192(66.4 \%)$ did not report any loss of interest in other people or activities, 213 $(72.7 \%)$ said they felt they were decisive, 247 $(85.5 \%)$ did not report worthlessness, 62 (21.5\%) reported no loss in energy, $106(36.7 \%)$ did not report any changes in sleep patterns, $153(52.9 \%)$ did not report increased irritability, $119(41.3 \%)$ did not report changes in appetite, $160(55.4 \%)$ reported no changes in concentration levels, $64(22.1 \%)$ did not detect increased fatigue while 99 (35.7\%) did not report any changes in sexual interest. The average score was 12.8 (std dev 8.7), with the most common symptoms of depression being the loss of energy $(78.5 \%)$ and increased fatigue $(77.9 \%)$.

\section{Prevalence of Depression}

As shown in Table 3 below, 135 (46.7\%) reported no depression, 72 (24.9\%) had mild mood disturbances, $33(11.4 \%)$ had borderline clinical depression, 37 (12.8\%) had moderate depression, 8 (2.8\%) had severe depression and $4(1.4 \%)$ had extreme depression. In summary, the prevalence of depression (borderline clinical depression to extreme depression) was $82(28.4 \%)$.

Table 3: Prevalence of Depression

\begin{tabular}{llll}
\hline Prevalence of Depression & N & \% \\
\hline \multirow{4}{*}{ Level of depression } & No depression & 135 & 46.7 \\
& Mild mood disturbances & 72 & 24.9 \\
& Borderline clinical depression & 33 & 11.4 \\
& Moderate depression & 37 & 12.8 \\
& Severe depression & 8 & 2.8 \\
\cline { 2 - 3 } Depression & Extreme depression & 4 & 1.4 \\
\hline & No depression to Mild mood disturbances & 207 & 71.6 \\
& Borderline clinical depression to extreme depression & 82 & 28.4 \\
\hline
\end{tabular}

\section{Factors Associated with Depression}

As shown in Table 4 below, depression scores appeared to be higher in; females $(p=0.09)$, those separated $(p=0.379)$, those with low income
(0.474), and in Muslims and other religions (0.709), but the differences were not statistically significant. However, lower education $(p=0.007)$ and being unemployed $(p=0.031)$ appeared to be associated with higher depression scores and were statistically significant.

Table 4: Factors associated with depression

\begin{tabular}{|c|c|c|c|c|}
\hline \multirow[t]{2}{*}{ Factors } & & \multicolumn{3}{|c|}{ Total Score } \\
\hline & & Mean & Standard Deviation & p-value \\
\hline \multirow{2}{*}{ Sex } & Male & 12.0 & 8.3 & \multirow{2}{*}{0.090} \\
\hline & Female & 13.8 & 9.0 & \\
\hline \multirow{5}{*}{ Marital status } & Single & 12.7 & 9.3 & \multirow{5}{*}{0.379} \\
\hline & Married & 12.7 & 8.5 & \\
\hline & Separated & 16.9 & 9.6 & \\
\hline & Widowed & 9.5 & 5.7 & \\
\hline & Cohabiting & & & \\
\hline$\overline{\text { Education level }}$ & No formal education & 20.2 & 2.6 & 0.007 \\
\hline
\end{tabular}

43 This work is licensed under a Creative Commons Attribution 4.0 International License. 
East African Journal of Health and Science, Volume 5, Issue 1, 2022

Article DOI: https://doi.org/10.37284/eajhs.5.1.571

\begin{tabular}{|c|c|c|c|c|}
\hline \multirow[t]{2}{*}{ Factors } & & \multicolumn{3}{|c|}{ Total Score } \\
\hline & & Mean & Standard Deviation & p-value \\
\hline & Primary & 15.1 & 9.2 & \\
\hline & Secondary & 11.5 & 8.2 & \\
\hline & Tertiary & 12.4 & 8.7 & \\
\hline \multirow{6}{*}{ Occupation } & Student & 8.7 & 5.0 & \multirow{6}{*}{0.031} \\
\hline & Formal employment & 12.9 & 9.8 & \\
\hline & Informal employment & 12.8 & 7.5 & \\
\hline & Businessperson & 11.7 & 8.2 & \\
\hline & Unemployed & 14.9 & 9.2 & \\
\hline & More than one category & & . & \\
\hline \multirow{5}{*}{ Income } & Less than 6000 & 13.0 & 8.5 & \multirow{5}{*}{0.474} \\
\hline & $6000-10000$ & 12.4 & 7.5 & \\
\hline & $10000-40000$ & 13.8 & 9.8 & \\
\hline & $40000-100000$ & 10.4 & 8.0 & \\
\hline & $>100000$ & 12.0 & 12.0 & \\
\hline \multirow{4}{*}{ Religion } & Catholic & 12.2 & 9.1 & \multirow{4}{*}{0.706} \\
\hline & Protestant & 13.0 & 8.1 & \\
\hline & Muslim & 14.7 & 12.3 & \\
\hline & Others & 15.5 & 7.8 & \\
\hline
\end{tabular}

\section{Psychiatric History, Medical History, Substance Use and Depression}

As shown in Table 5 below, 11 (3.8\%) of the participants had a family history of mental illnesses, and $5(1.7 \%)$ had a history of mental illness. Additionally, 201 (69.8\%) had another physical illness, and $20(7.2 \%)$ were using alcohol and other substances. There was a statistically significant relationship between the presence of other physical illnesses and depression ( $p=0.005)$. However, there was no statistically significant association between depression and having had a history of mental illness in the family. There was also no statistically significant connection between depression and having a history of mental illness or use of substances.

Table 5: Psychiatric history, medical history, substance use and depression

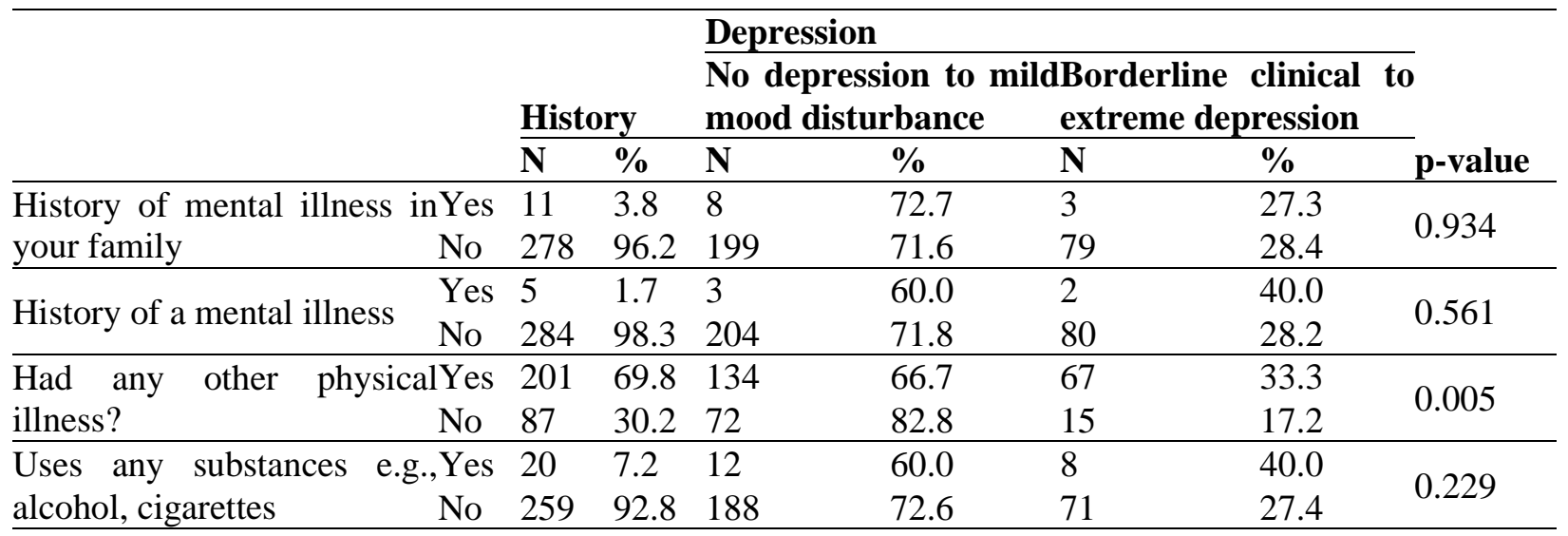

Further investigations on other illnesses found that depression was associated with having hypertension $(p=0.008)$. This means that hypertensive people were likely to report borderline to extreme depression, as in Table 6 below.

44 | This work is licensed under a Creative Commons Attribution 4.0 International License. 
Table 6: Hypertension and depression

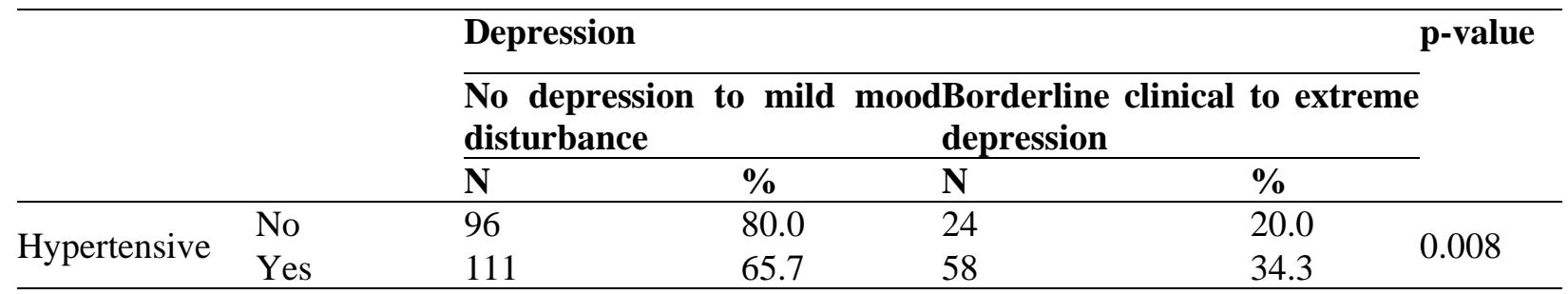

\section{DISCUSSION}

\section{Socio-Demographic}

Two hundred and eight-nine participants were interviewed with the enrolment mean age of participants standing at 45.9 years. This can be explained by the fact that the risk of developing noncommunicable diseases increases with age (Dixon, 2016). Most of the participants were male even though the Kenya Demographic and Health Survey 2014 showed that females are likely to report having been diagnosed with hypertension by a health care provider up to 3 times more than men (Kenya Population and Housing Census, 2019). This high number of male respondents compared to the females may be because men tend to have poor health-seeking behaviour and they often go to the hospital when they already have complications as CKD is a complication of hypertension. Other studies were done in the USA, Asia, the Middle East and Africa and they also had higher samples of males than females (Hedayati et al., 2010; Amira et al., 2011; Chiang et al., 2017).

Most participants were Christians. Additionally, there were more Protestants than Catholics. This can be explained by the fact that the most recent national census in Kenya done in 2019 showed that $85.5 \%$ of the population are Christians and that among them, 33.4\% are Protestants, $20.4 \%$ are affiliated with Evangelical churches and $20.6 \%$ are Catholic (Kenya Population and Housing Census, 2019). The majority of the participants had completed secondary education. A significant number of them were either employed or business owners. Slightly more than a quarter were unemployed. Of those who were employed or in business, the majority were earning below 6,000 .

\section{Depression Symptoms}

The most common symptoms of depression reported by the participants were fatigue $(77.9 \%)$ and loss of energy $(78.5 \%)$. While these are symptoms of depression, they are also very common symptoms of CKD itself (Ndetei et al., 2009). That explains why most of the participants reported them in this study.

\section{Prevalence of Depression}

The prevalence of depression was found to be $28.4 \%$. This is similar to studies done in the USA, Europe, Asia, Middle East and one study done in Africa, despite the use of different research tools [1, 8,14]. In Asia, a study done in Malaysia found a much higher incidence of depression in CKD patients of 71-84\% (Khan et al., 2019). This study used Becks Depression Inventory (BDI) as the screening tool for depression, and the tool was administered to hypertensive CKD patients on dialysis on three different visits. With every dialysis visit, the prevalence of depression got higher in that sample population (Khan et al., 2019). Similarly, another study done in the Middle East found an equally high prevalence of $70 \%$ using the Hamilton rating scale for depression (HAM-D) (Hawamdeh et al., 2017). A study was done in Ghana and established a $44 \%$ frequency of depression which is higher than what this study found. The screening tool used in that study was the PHQ-9, while this study used the BDI-II (Ganu et al., 2018).

\section{Factors associated with depression}

In the study, being unemployed $(p=0.031)$ was reported to be related to high depression risk. This is similar in other studies as well. For instance, a study done in Saudi Arabia found that depression was higher in patients on haemodialysis with a lower socioeconomic status (Mosleh et al., 2020). 
This association can be explained by the fact that treatment for CKD is very expensive and causes a lot of economic strain on these patients and their families [26]. The connection between lower education level and having depression was statistically significant $(p=0.007)$. This is similar to what has been demonstrated in other studies including a study in Ghana by (Ganu et al., 2018). Knowledge of one's chronic illness has been reported to be associated with better coping mechanisms in those who are educated as opposed to those who are not educated.

\section{Medical History and Depression}

This study shows that having a physical illness together with chronic kidney disease is associated with having depression $(p=0.005)$. Having hypertension particularly was linked to a higher chance of having depression $(p=0.008)$. This has also been demonstrated in other studies globally (Bahall et al., 2020; Jahrami et al., 2020).

\section{CONCLUSION}

There is a high occurrence of depression among patients with CKD. Further, lower education, unemployment and having another illness such as hypertension are significantly associated with depression.

\section{Recommendations}

- Patients should be managed effectively for CKD and any other co-existing comorbidity to improve their health outcomes.

- Health care workers managing patients for CKD need to be keen to look for depression in them and manage it to give holistic care.

- There is a need to come up with local guidelines on how to effectively manage CKD patients who also have depression in our country to better their standard of life.

- There is a need for a follow-up study on the most efficacious treatment for depression among patients with chronic kidney disease in our local setup in Kenya.

\section{Strengths and Limitations of the study}

A strength of this study was the fact that it was carried out at a National Teaching and Referral hospital in Kenya and so the patients recruited were from all over the country. Patients were diverse and so the results give a picture of the situation in the country. Another strength of the study was the fact that there were many patients and the target sample size was achieved with ease. One limitation of the study was that the other physical illnesses reported by the patients in the study other than hypertension were not analysed.

\section{REFERENCES}

Amira, O. (2011). Prevalence of symptoms of depression among patients with chronic kidney disease. Nigerian Journal of clinical practice, 14(4), 460-463.

Bahall, M., Legall, G., Khan, K. (2020). Quality of life among patients with cardiac disease: the impact of comorbid depression. Health and quality of life outcomes, 18(1):1-0.

Bautovich, A., Katz, I., Smith, M., Loo, C. K., \& Harvey, S. B. (2014). Depression and chronic kidney disease: A review for clinicians. Australian \& New Zealand Journal of Psychiatry, 48(6), 530-541.

Beck, A. T., Steer, R. A., \& Brown, G. K. (1996). Beck depression inventory (BDIII) (Vol. 10, p. s15327752jpa6703_13). Pearson.

Chiang, H. H., Guo, H. R., Livneh, H., Lu, M. C., Yen, M. L., \& Tsai, T. Y. (2015). Increased risk of progression to dialysis or death in CKD patients with depressive symptoms: A prospective 3-year follow-up cohort study. Journal of psychosomatic research, 79(3), 228-232.

Couser, W. G., Remuzzi, G., Mendis, S., \& Tonelli, M. (2011). The contribution of chronic kidney disease to the global burden of major noncommunicable diseases. Kidney international, 80(12), 1258-1270.

Da Silva Junior, G. B., de Oliveira Barbosa, A. M., da Silva, G. P. F., da Silva, L. N., Lima, G. R.,

46 This work is licensed under a Creative Commons Attribution 4.0 International License. 
Santana, C. C., ... \& Araújo, S. M. H. A. (2017). Depressive symptoms in chronic kidney disease: A comparison between patients on dialysis versus conservative treatment. Nefrología Latinoamericana, 14(4), 153-159.

Dhondup, T., Kittanamongkolchai, W., Vaughan, L. E., Mehta, R. A., Chhina, J. K., Enders, F. T., Hickson, L. J., Lieske, J. C., \& Rule, A. D. (2018). Risk of ESRD and Mortality in Kidney and Bladder Stone Formers. American journal of kidney diseases : the official journal of the National Kidney Foundation, 72(6), 790-797. https://doi.org/10.1053/j.ajkd.2018.06.012

Dixon, J. (Ed.). (2016). Social welfare in Africa. Routledge.

Farragher, J. F., Polatajko, H. J., \& Jassal, S. V. (2017). The relationship between fatigue and depression in adults with end-stage renal disease on chronic in-hospital haemodialysis: a scoping review. Journal of pain and symptom management, 53(4), 783-803.

Fischer, M. J., Kimmel, P. L., Greene, T., Gassman, J. J., Wang, X., Brooks, D. H., Charleston, J., Dowie, D., Thornley-Brown, D., Cooper, L. A., Bruce, M. A., Kusek, J. W., Norris, K. C., Lash, J. P., \& AASK Study Group (2011). Elevated depressive affect is associated with adverse cardiovascular outcomes among African Americans with chronic kidney disease. Kidney international, 80(6), 670-678. https://doi.org/1 $0.1038 / \mathrm{ki} .2011 .153$

Ganu, V. J., Boima, V., Adjei, D. N., Yendork, J. S., Dey, I. D., Yorke, E., Mate-Kole, C. C., \& MateKole, M. O. (2018). Depression and quality of life in patients on long term hemodialysis at a nationalhospital in Ghana: a cross-sectional study. Ghana medical journal, 52(1), 22-28. https://doi.org/10.4314/gmj.v52i1.5

Gregg, L. P., Carmody, T., Le, D., Martins, G., Trivedi, M., \& Hedayati, S. S. (2020). A Systematic Review and Meta-Analysis of Depression and Protein-Energy Wasting in Kidney Disease. Kidney international reports, 5(3), 318-330.
Hawamdeh, S., Almari, A. M., Almutairi, A. S., \& Dator, W. L. T. (2017). Determinants and prevalence of depression in patients with chronic renal disease, and their caregivers. International journal of nephrology and renovascular disease, 10, 183.

Hedayati, S. S., Minhajuddin, A. T., Afshar, M., Toto, R. D., Trivedi, M. H., \& Rush, A. J. (2010). Association between major depressive episodes in patients with chronic kidney disease and initiation of dialysis, hospitalisation, or death. Jama, 303(19), 1946-1953.

Jahrami, H., Saif, Z., AlHaddad, M., Hammad, L., Ali, B. (2020). Assessing dietary and lifestyle risk behaviours and their associations with disease comorbidities among patients with depression: A case-control study from Bahrain. Heliyon, 6(6):e04323.

Kenya Population and Housing Census. (2019). Distribution of Population by Administrative Units. KNBS. Vol. II. http://www.knbs.or.ke.

Khan, A., Khan, A. H., Adnan, A. S., Sulaiman, S. A. S., \& Mushtaq, S. (2019). Prevalence and predictors of depression among haemodialysis patients: a prospective follow-up study. $B M C$ public health, 19(1), 1-13.

Kokoszka, A., Leszczyńska, K., Radzio, R., Daniewska, D., Łukasiewicz, A., Orzechowski, W. M., ... \& Gellert, R. (2016). Prevalence of depressive and anxiety disorders in dialysis patients with chronic kidney disease. Arch Psychiatry Psychother, 1, 8-13.

Liu, X., Yang, X., Yao, L., Zhang, Q., Sun, D., Zhu, X., Xu, T., Liu, Q., \& Wang, L. (2017). Prevalence and related factors of depressive symptoms in hemodialysis patients in northern China. BMC psychiatry, 17(1), 128. https://doi.org/10.1186/s12888-017-1294-2

Loosman, W. L., Rottier, M. A., Honig, A., \& Siegert, C. E. (2015). Association of depressive and anxiety symptoms with adverse events in Dutch chronic kidney disease patients: a prospective cohort study. BMC nephrology, 16(1), 1-8. 
Mosleh, H., Alenezi, M., Alsani, A., Fairaq, G., \& Bedaiwi, R. (2020). Prevalence and factors of anxiety and depression in chronic kidney disease patients undergoing hemodialysis: A cross sectional single-center study in Saudi Arabia. Cureus, 12(1).

Musyimi, C. W., Mutiso, V. N., Nayak, S. S., Ndetei, D. M., Henderson, D. C., \& Bunders, J. (2017). Quality of life of depressed and suicidal patients seeking services from traditional and faith healers in rural Kenya. Health and quality of life outcomes, 15(1), 1-10.

Naing, L., Winn, T. B. N. R., \& Rusli, B. N. (2006). Practical issues in calculating the sample size for prevalence studies. Archives of orofacial Sciences, 1, 9-14.

Ndetei, D. M., Khasakhala, L. I., Kuria, M. W., Mutiso, V. N., Ongecha-Owuor, F. A., \& Kokonya, D. A. (2009). The prevalence of mental disorders in adults in different level general medical facilities in Kenya: a crosssectional study. Annals of general psychiatry, 8(1), 1-8.

Palmer, S., Vecchio, M., Craig, J. C., Tonelli, M., Johnson, D. W., Nicolucci, A., Pellegrini, F., Saglimbene, V., Logroscino, G., Fishbane, S., \& Strippoli, G. F. (2013). Prevalence of depression in chronic kidney disease: systematic review and meta-analysis of observational studies. Kidney international, 84(1), 179- 191. https://doi.org/1 0.1038/ki.2013.77

Sfyrkou, C. (2015). Psychological distress and multimorbidity in patients with chronic kidney disease.

Shirazian, S., Grant, C. D., Aina, O., Mattana, J., Khorassani, F., \& Ricardo, A. C. (2017). Depression in chronic kidney disease and endstage renal disease: similarities and differences in diagnosis, epidemiology, and management. Kidney international reports, 2(1), 94-107. 